\title{
Fenómeno de Raynaud
}

\author{
Pablo Franquelo Moralesa , Alicia Panadero Sáncheza, \\ Félix González Martíneza, Susana Losada Ruiza .
}

\begin{abstract}
a Servicio de Urgencias. Hospital Virgen de la Luz, Cuenca.
\end{abstract}

\section{Correspondencia: \\ Pablo Franquelo \\ Morales, Servicio de \\ Urgencias, Hospital Virgen de la Luz, C/ Hermandad de Donantes de Sangre $n^{\circ} 2$, 16002-Cuenca. \\ E-mail: pfranquelo@yahoo.es.}

Recibido el 29 de octubre de 2008

Aceptado para su publicación el 2 de diciembre de 2008.

\section{RESUMEN}

El fenómeno de Raynaud se caracteriza por una disminución de la circulación sanguínea, fundamentalmente en los dedos de las manos y de los pies, con dolor y cambios de coloración en la piel de una forma secuencial: blanco, azul y rojo. Es más frecuente en las mujeres, en la $2^{\mathrm{a}}$ y $3^{\mathrm{a}}$ décadas de la vida. Se desconoce cuál es su causa, pero guarda relación con el consumo de tabaco, alcohol, y fundamentalmente con los cambios de temperatura y alteraciones emocionales. Se asocia a enfermedades del tejido conectivo, entre las que Esclerodermia y Lupus son las más frecuentes. El Nifedipino es el fármaco de primera elección.

Palabras clave. Enfermedad de Raynaud. Cambios en la Temperatura Corporal. Nifedipino.

\section{ABSTRACT}

Raynaud's Phenomenon

Raynaud's phenomenon is characterized by a decrease in blood circulation mainly in the fingers and toes, with pain and changes in skin colour which follow a characteristic pattern white, blue and red. It is more common in women, in the 2 nd and 3rd decade of life. The cause is unknown, but is related to smoking and alcohol consumption, and particularly body temperature changes and emotional stress. It is associated with connective tissue diseases amongst which scleroderma and lupus are the most frequent. Nifedipine is the treatment of choice.

Key words. Raynaud Disease. Body Temperature Changes. Nifedipine.

\section{INTRODUCCIÓN}

El fenómeno de Raynaud se caracteriza por una disminución de la circulación sanguínea en los dedos de las manos y de los pies, produciéndose dolor y cambios de coloración que en ocasiones pueden afectar a otras zonas como labios, nariz, lóbulos de las orejas, lengua y mentón ${ }^{1-5}$.

Fue descrito por primera vez en 1862 cuando un estudiante de medicina llamado Maurice Raynaud observó este fenómeno en las manos, fundamentalmente de las mujeres, cuando se exponían al frío intenso del invierno.

\section{OBSERVACIONES CLÍNICAS}

Presentamos el caso de una mujer de 44 años que consultó por episodios autolimitados de frialdad sin causa aparente a nivel del $2^{\circ}$ dedo de la mano derecha, con dolor y coloración azulada en los últimos días. Recientemente los síntomas no desaparecían, por lo que angustiada decidió consultar. En la exploración presentaba una coloración azulada del $2^{\circ}$ dedo de la mano derecha (figura 1).Tras sumergir el dedo en agua fría durante un periodo de 5 minutos, se apreció un aumento de la coloración azulada y reproducción del dolor. Tranquilizamos a la paciente y pautamos tratamiento con nifedipino $10 \mathrm{mg}$ cada 12 horas hasta nueva revisión.

\section{COMENTARIOS}

El Fenómeno de Raynaud aparece con mayor frecuencia en las mujeres, entre la $2^{\mathrm{a}}$ y $3^{a}$ décadas de la vida, y aunque su etiología resulta desconocida se relaciona con 


\section{Enfermedades vasculares oclusivas}

\section{Fármacos}

Infecciones

Síndromes endocrinos, neurológicos, hematológicos y cáncer

\section{Causas ambientales}

Síndromes anatómicos
Lupus eritematoso sistémico, Esclerodermia, Síndrome de Sjögren,

Artritis reumatoide, Enfermedad mixta del tejido conectivo, Polimiositis,

Síndrome CREST (depósitos de calcio en la piel, fenómeno de Raynaud,

dismotilidad esofágica, esclerodactilia, telangiectasia), Enfermedad de Buerger,

Arterioesclerosis, Trombocitosis, Vasculitis Células Gigantes,

Hipertensión pulmonar primaria, Arteritis de Takayasu

Betabloqueantes, Estrógenos, Cloruro de polivinilo, Triptanes, Ergotamínicos, Anticonceptivos, Bleomicina, Interferon alfa, Vinblastina, Anfetaminas,

Ciclosporina, Bromocriptina, Cisplatino

Hepatitis B y C, Parvovirus, Micoplasma

Mieloma múltiple, Policitemia, Crioglobulinemia, Mixedema, Hipotiroidismo,

Feocromocitoma, Diabetes mellitus, Hipovitaminosis, Sindrome carcinoide,

Sarcoidosis, Acromegalia, Helicobacter Pylori ${ }^{9}$, Hemipeljía, Tabes dorsal,

Insuficiencia renal crónica, Enf.de Fabry, Sirnigomielia, Enf. de Parkinsosn

Tabaco, Envenenamiento por plomo, Alcohol, Máquinas vibradoras, Cocaína

Síndrome del desfiladero torácico, Síndrome del túnel carpiano,

Costilla cervical

Tabla 1. Causas de Fenómeno de Raynaud secundario.

Episodios de vasoespasmo tras exposición al frío o estrés Ataques simétricos con compromiso de ambas manos

Ausencia de edema, ulceración o necrosis

No presencia de enfermedad causal

Capilaroscopia normal

Velocidad de Sedimentación Globular (VSG) $<20$ mm/h

Anticuerpos Antinucleares bajos o negativos ANA $<1 / 100$

Tabla 2. Criterios diagnósticos de Fenómeno de Raynaud primario.

factores de riesgo como el tabaco y el alcohol, pero son los cambios de temperatura, fundamentalmente el frío, y las alteraciones emocionales los factores precipitantes. Cuando ocurre sin causa aparente se de- nomina fenómeno de Raynaud primario o enfermedad de Raynaud (ER) cuya prevalencia es del $4-5 \%$ y cumple unos criterios establecidos (tabla 2). La presencia de una enfermedad asociada, con mayor frecuencia de tejido conectivo (80\%), constituye un fenómeno de Raynaud secundario (FRS) ${ }^{6}$, entre ellas la Esclerodermia y el Lupus eritematoso sistémico son las más habituales (tabla 1). Los síntomas consisten en cambios secuenciales en la coloración de la piel, con una primera tonalidad blanca, por isquemia, un color azul, por estasis sanguíneo, y finalmente una fase hiperémica y dolorosa por la restitución del flujo sanguíneo, de color rojo. Es necesario al menos dos de los tres cambios de coloración, pudiéndose acompañar de hinchazón y parestesias. El diagnóstico es clínico, reproduciéndose los cambios de coloración al exponer

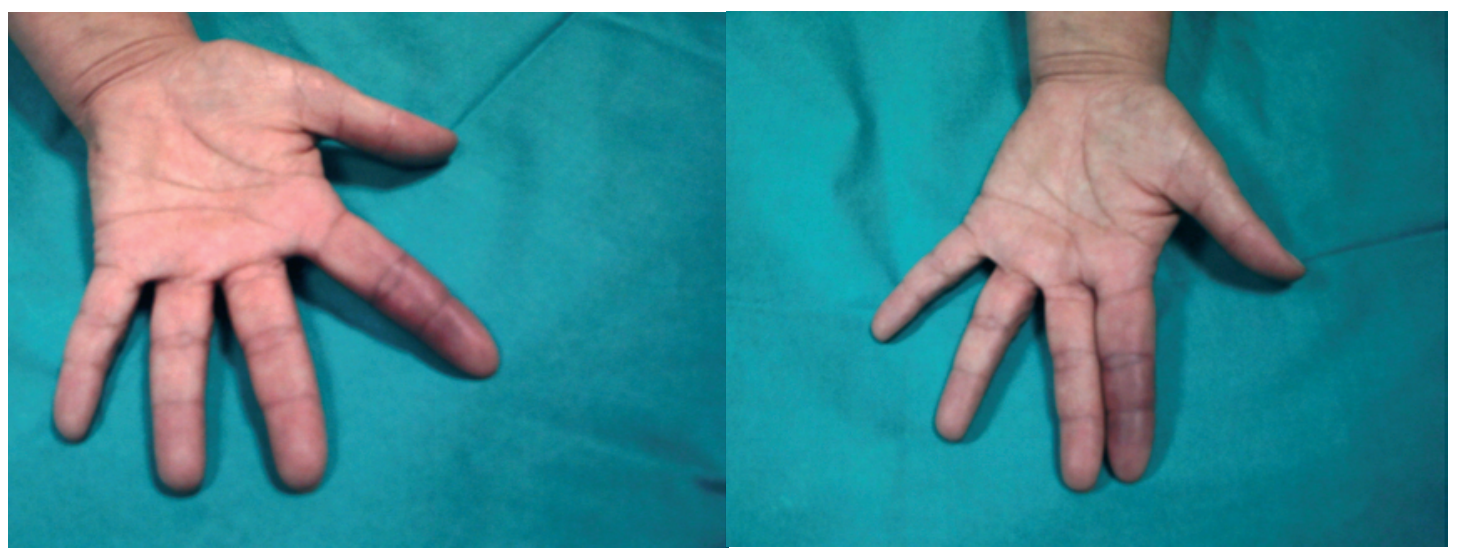

Figura 1. Aumento de coloración en el $2^{\circ}$ dedo de la mano izquierda. 
la zona afectada al frío, así como el examen de la morfología vascular bajo un microscopio (capilaroscopia). El objetivo del tratamiento es prevenir los ataques y evitar la afectación de tejidos por hipoxemia. Esto se consigue protegiéndose del frío, evitando el estrés emocional y la utilización de máquinas con vibración, así como el abandono del tabaco ${ }^{8}$. Diversos vasodilatadores, como el nifedipino, reducen la frecuencia y severidad de los ataques ${ }^{6,7,9}$, constituyendo el fármaco de elección junto a diltiazem y nitroglicerina. Sin tratamiento, el FRS puede ocasionar úlceras, que se pueden infectar y gangrenar, requiriendo amputación en un $10 \%$ de los casos. Esto es difícil que suceda en la $E F$, lo que constituye una importante diferencia. En los casos severos se recurre a la simpatectomía de los nervios que producen la vasoconstricción. En conclusión, los pacientes que consultan por una manifestación de Fenómeno de Raynaud deben ser evaluados para determinar si existe una enfermedad subyacente, generalmente del tejido conectivo.

\section{BIBLIOGRAFÍA}

1. Boin F, Wigley FM. Understanding, assessing and treating Raynaud's phenomenon. Curr Opin Rheumatol 2005; 17:752-60.

2. Herrick AL. Pathogenesis of Raynaud's phenomenon. Rheumatology 2005; 44:587-96.

3. Pope J. Raynaud's phenomenon (primary). Clin Evid 2005; 13:1546-54

4. Suter LG, Murabito JM, Felson DT, Fraenkel L. The incidence and natural history of Raynaud's phenomenon in the community. Arthritis Rheum 2005; 52:1259-63.

5. Thompson AE, Pope JE. Calcium channel blockers for primary Raynaud's phenomenon: a meta-analysis. Rheumatology 2005; 44:145-50.

6. Suter LG, Murabito JM, Felson DT, Fraenkel L. Smoking, alcohol consumption, and Raynaud's phenomenon in middle age. Am J Med 2007; 120:264-71.

7. Bakst R, Merola JF, Franks AG Jr, Sanchez M. Raynaud's phenomenon: pathogenesis and management. J Am Acad Dermatol 2008; 59:633-53.

8. Block JA, Sequeira W. Raynaud's phenomenon. Lancet 2001; 23:2042-48.

9. Gasbarrini A, Massari I, Serricchio M, Tondi P, De Luca A, Franceschi $\mathrm{F}$ et al. Helicobacter pylori eradication ameliorates primary Raynaud's phenomenon. Dig Dis Sci 1998; 43:1641-5. 